\title{
Epstein-Barr virus IL-10 gene expression by a recombinant murine gammaherpesvirus in vivo enhances acute pathogenicity but does not affect latency or reactivation
}

\author{
Gary J Lindquester ${ }^{1 *}$, Kimberly A Greer ${ }^{1}$, James P Stewart ${ }^{2}$ and Jeffery T Sample Ka $^{3,4}$
}

\begin{abstract}
Background: Many viral genes affect cytokine function within infected hosts, with interleukin 10 (IL-10) as a commonly targeted mediator. Epstein-Barr virus (EBV) encodes an IL-10 homologue (vIL-10) expressed during productive (lytic) infection and induces expression of cellular IL-10 (CIL-10) during latency. This study explored the role of VIL-10 in a murine gammaherpesvirus (MHV) model of viral infection.

Methods: The EBV VIL-10 gene was inserted into MHV-76, a strain which lacks the ability to induce cIL-10, by recombination in transfected mouse cells. Mice were infected intranasally with the recombinant, vlL-10-containing MHV-76 or control virus strains and assayed at various days post infection for lung virus titer, spleen cell number, percentage of latently infected spleen cells and ability to reactivate virus from spleen cells.

Results: Recombinant murine gammaherpesvirus expressing EBV VIL-10 rose to significantly higher titers in lungs and promoted an increase in spleen cell number in infected mice in comparison to MHV strains lacking the vIL-10 gene. However, VIL-10 expression did not alter the quantity of latent virus in the spleen or its ability to reactivate.

Conclusions: In this mouse model of gammaherpesvirus infection, EBV VIL-10 appears to influence acute-phase pathogenicity. Given that EBV and MHV wild-type strains contain other genes that induce ClL-10 expression in latency (e.g. LMP-1 and M2, respectively), vLL-10 may have evolved to serve the specific role in acute infection of enlarging the permissive host cell population, perhaps to facilitate initial survival and dissemination of viral-infected cells.
\end{abstract}

Keywords: Gammaherpesvirus, Epstein-Barr virus, IL-10, Interleukin 10, Immune modulation

\section{Background}

Viruses from a range of virus families exert direct influence on host cytokine responses. Such influence can be mediated through expression of viral homologs of host cytokines or cytokine receptors, or through expression of viral factors that alter expression of host cytokines [1-3]. Several herpesviruses such as Epstein-Barr virus (EBV) [4], equid herpesvirus 2 [5], ovine herpesvirus 2 [6], and primate cytomegaloviruses [7-9] encode a homolog to the IL-10 gene. Infection of $B$ cells by EBV results in expression of virusencoded IL-10 (vIL-10, encoded by the BCRF1 gene) as

\footnotetext{
* Correspondence: glindquester@rhodes.edu

'Department of Biology, Rhodes College, Memphis, TN 38112, USA Full list of author information is available at the end of the article
}

well as induction of the endogenous cellular IL-10 (cIL-10) gene. vIL10 mRNA is detectable within six hours of EBV infection in vitro [10] and thus is expressed early in infection [11]. In fact, EBV virions carry a number of viral mRNAs including those encoding vIL-10, which may be translated immediately upon infection [12]. Subsequently, expression of the cIL-10 gene is induced twenty to forty hours post-EBV infection $[10,13,14]$ and is upregulated by the EBV latency-associated LMP-1 and small non-coding RNAs (EBERs) [15,16]. The differential timing of expression of these two IL-10 forms may reflect differences in their respective roles in viral infection.

IL-10 is a highly pleotropic, regulatory cytokine with differential effects in T-cell populations that generally 
reduce inflammation and cytotoxic responses, while favoring a humoral immune response [17]. The EBV vIL-10 [4], like its cellular counterpart, inhibits cytokine synthesis [18]. EBV vIL-10 is $84 \%$ homologous to human IL-10, with most divergence occurring at the $\mathrm{N}$ terminus [4] resulting in an altered N-terminal structure [19]. cIL-10 and vIL-10 enhance B-cell viability, whereas only cIL-10 upregulates MHC II on B cells [20]. vIL-10 also lacks cIL-10's ability to stimulate mast cells [21] and to induce proliferation of mature and immature thymocytes [22]. EBV vIL-10 has 1000 -fold lower affinity for the IL-10 receptor, perhaps explaining its greatly reduced ability to inhibit IL-2 production by helper $\mathrm{T}$ cells [23]. Thus, the viral and cellular homologs share many immunosuppressive activities, while vIL-10 generally lacks cIL-10's immunostimulatory functions. These differences are attributed primarily to a single amino acid substitution [24].

In earlier studies involving an EBV mutant in which the vIL-10-encoding gene was deleted, vIL-10 was concluded to have no effect on replication, immortalization and establishment of latency within B cells in vitro, and to have no effect on tumorigenicity when the resulting EBV-infected B lymphoblastoid cell lines were injected into SCID mice [11]. More recent in vitro studies with vIL-10-deficient EBV virus have demonstrated that vIL-10's early expression protects infected B cells by altering the cytokine response, reducing NK cell killing, and inhibiting $\mathrm{CD} 4+\mathrm{T}$ cell activity [12]. In vivo, expression of the vIL-10 gene of the betaherpesvirus rhesus cytomegalovirus (RhCMV), significantly limits innate immune responses to primary infection, which in turn reduces both T- and B-cell responses [25]. However, the applicability of the latter study to understanding EBV vIL-10 function is questionable given the low (27\%) homology of RhCMV vIL-10 with cIL-10 [9] and the high binding affinity of RhCMV vIL-10 relative to EBV vIL-10 for the IL-10 receptor [26]. To date, studies probing the nuances of EBV vIL-10 in gammaherpesvirus infection have not been presented in an in vivo model of viral pathogenicity.

Murine gammaherpesvirus 68 (MHV-68, $\gamma \mathrm{HV} 68$, murid herpesvirus 4) infection of laboratory mice serves as a tractable animal model for gammaherpesvirus pathogenesis [27]. Upon intranasal (i.n.) inoculation of mice, MHV-68 rapidly establishes an acute, productive infection of alveolar epithelial cells which is essentially cleared about 10 days post-infection (p.i.) [28]. As the acute phase resolves, a syndrome similar to EBV-induced infectious mononucleosis ensues. This phase is characterized by splenomegaly [29], non-antigen-specific B-cell activation [30], and peripheral blood lymphocytosis primarily reflecting the expansion of CD8+ T cells expressing a V 34 T-cell receptor [31]. This syndrome peaks at day 14 p.i. and resolves by about day 21 p.i. Latent virus has been detected in peritoneal macrophages [32], splenic macrophages and dendritic cells [33], and $\mathrm{B}$ cells [33-36]. B cells are likely to be the means for trafficking MHV-68 from the lung to the spleen [37] and expression of vtRNAs, a marker for latency, has been localized to the germinal centers in the spleen [38-40]. $\mathrm{CD} 4+\mathrm{T}$ cells are required for MHV-68-induced splenomegaly $[29,41]$, while CD8 $+\mathrm{T}$ cells are critical for limiting productive pulmonary infection and for the resolution of splenomegaly [35,41-43].

MHV-76, a variant of MHV-68, contains a deletion of $9538 \mathrm{bp}$ within the left end of the unique-sequence domain of the MHV-68 prototype genome - the region which includes the MHV-68 genes M1-M4 as well as eight vtRNA genes [44,45]. In comparison to MHV-68, MHV-76 is cleared more rapidly from the lungs and induces less pronounced splenomegaly and fewer numbers of latently infected cells in the spleen, although replication of the viruses in culture does not differ [44,45]. The M2 gene encodes a latency-associated protein that serves as a target for cell-mediated immunity [46]. The M2 protein binds Vav signaling proteins and promotes cell proliferation and survival [47]. MHV-68 strains lacking only M2 expression show the same reduction in latency and reactivation as MHV-76; however, they do not exhibit MHV-76's reduction of splenomegaly [48-50]. While MHV-68 does not carry a native vIL-10 gene, M2 stimulates cIL-10 expression $[51,52]$. It has been proposed that M2's role in stimulating cIL-10 and its resulting effects may represent a conserved gammaherpesvirus strategy that is also represented by the EBV vIL-10 gene [51], although, as noted above, the timing of vIL-10 expression differs from that of cIL-10 induction. Therefore, we sought to determine the effects of vIL-10 expression on viral pathogenesis in a murine gammaherpesvirus strain lacking $M 2$ (MHV-76). Here we show that vIL-10 expression by MHV-76 enhances spleen cell proliferation and viral titers in the lung during acute infection, but does not affect splenic latency or reactivation of virus replication from latently infected cells.

\section{Methods}

\section{Cell and virus culture}

All MHV strains were propagated in NIH-3T3 (ATCC) cells in DMEM (GIBCO) supplemented with $10 \%$ fetal bovine serum (HyClone), penicillin $(100 \mathrm{U} / \mathrm{ml})$ and streptomycin $(100 \mu \mathrm{g} / \mathrm{ml})($ GIBCO $)$ at $37^{\circ} \mathrm{C}$ in a humidified $5 \%$ $\mathrm{CO}_{2}$ atmosphere essentially as described [28]. Viral titers were determined in a serial dilution plaque assay by fixing $[10 \%$ formalin (Fisher)] and staining $[0.1 \%$ toluidine blue (LabChem)] 3-5 days p.i.

\section{Generation of recombinant viruses}

Promoter: Pgp150, the MHV-68 late gene promoter for the M7 gene (expressing gp150), was isolated from MHV-68 DNA by PCR amplification of a 660 base pair (bp) fragment that begins 3 bp upstream of the M7 ORF start codon and extends upstream. The Pgp150 primers 
(5'-GAGTAGATCTTAAGGGAGAGCGATGAGG-3' and 5'-CAGTAAGCTTGAGGGTTTTATAGCGTCAC-3') included BgIII and HindIII restriction enzyme sites at the upstream and downstream ends, respectively. Promoters were inserted into the BglII and HindIII sites of the pGL3-Basic (sans promoter) luciferase reporter plasmid (Promega). Luciferase expression assayed with the Dual-Luciferase system (Promega) confirmed the activity of the promoters in NIH-3T3 cells transfected (FuGene, Roche) with the resulting plasmids.

vIL-10: The vIL-10 gene (encoded by the EBV BCRF1 ORF) was amplified by PCR from EBV (Akata strain) DNA using primers that generated $N c o \mathrm{I}$ and $X b a \mathrm{I}$ restriction sites at the upstream and downstream ends, respectively. Primers were 5 '-GTGACCATGGAGCGAA GGTTAGTG-3' and 5' -AGTGTCTAGATGCACCCAT CTCCTGCTTC-3'. The amplified product was cloned into the Pgp150-containing plasmid in place of the luciferase gene to create the vIL-10 expression cassette. Positive ELISA (Pierce) confirmed vIL-10 expression from plasmids in transfected NIH-3T3 cells.

Targeting cassette: Plasmid pBS76LHE (courtesy of James Stewart) contains an approximately 3-kbp fragment from the left hand end (LHE) unique sequence of the MHV-76 genome [53] and was modified to generate pBS76LHE-TR as follows. A portion of a terminal repeat fragment and its immediately adjacent unique sequence was amplified from MHV-68 DNA by PCR under conditions favorable for GC rich sequences (Roche). Primers were 5' -AGGCAGGCACCAACAG-3' and 5'-CAGCATCAGCCCCGGATCTC-3'.
This fragment, designated TR, represents terminal repeat sequences immediately to the left (in the prototype orientation) of the LHE fragment in MHV-76. TR was inserted next to the LHE fragment in pBS76LHE to generate pBSLHE-TR; a BamHI site separates TR from LHE. Furthermore, PmeI restriction enzyme sites were inserted on either side of the TR-LHE sequence to be able to liberate the TR-LHE targeting cassette. Next, the vIL10 expression cassette was liberated from its plasmid as a fragment with a BglII restriction site on the upstream end and a BamHI restriction site on the downstream end. This fragment was inserted into the BamHI site of pBS76LHE-TR and restriction enzyme analysis revealed clones containing the expression cassette in either orientation bounded by the TR and LHE components. Figure 1 shows a general schematic of construction of the targeting cassette.

Recombination and purification: NIH-3T3 cells grown in 6-well plates were co-transfected using FuGene (Roche) with MHV-76 DNA ( $1 \mu \mathrm{g}$, isolated essentially as described [54]) and targeting cassette (2-3 $\mu \mathrm{g}$ of PmeI-digested targeting-construct plasmid). Following the development of plaques, cultures were harvested and subjected to three rapid freeze/thaw cycles to release cell-associated virus. Stocks were serially diluted to infect NIH-3 T3 cells in 96well plates. DNA was isolated from wells developing single plaques by QiaAmp (Qiagen) and screened by PCR for the presence of the vIL-10 gene. This limiting-dilution screening was repeated for five or six rounds until all plaques were PCR positive for vIL-10. Positive ELISA (Pierce)

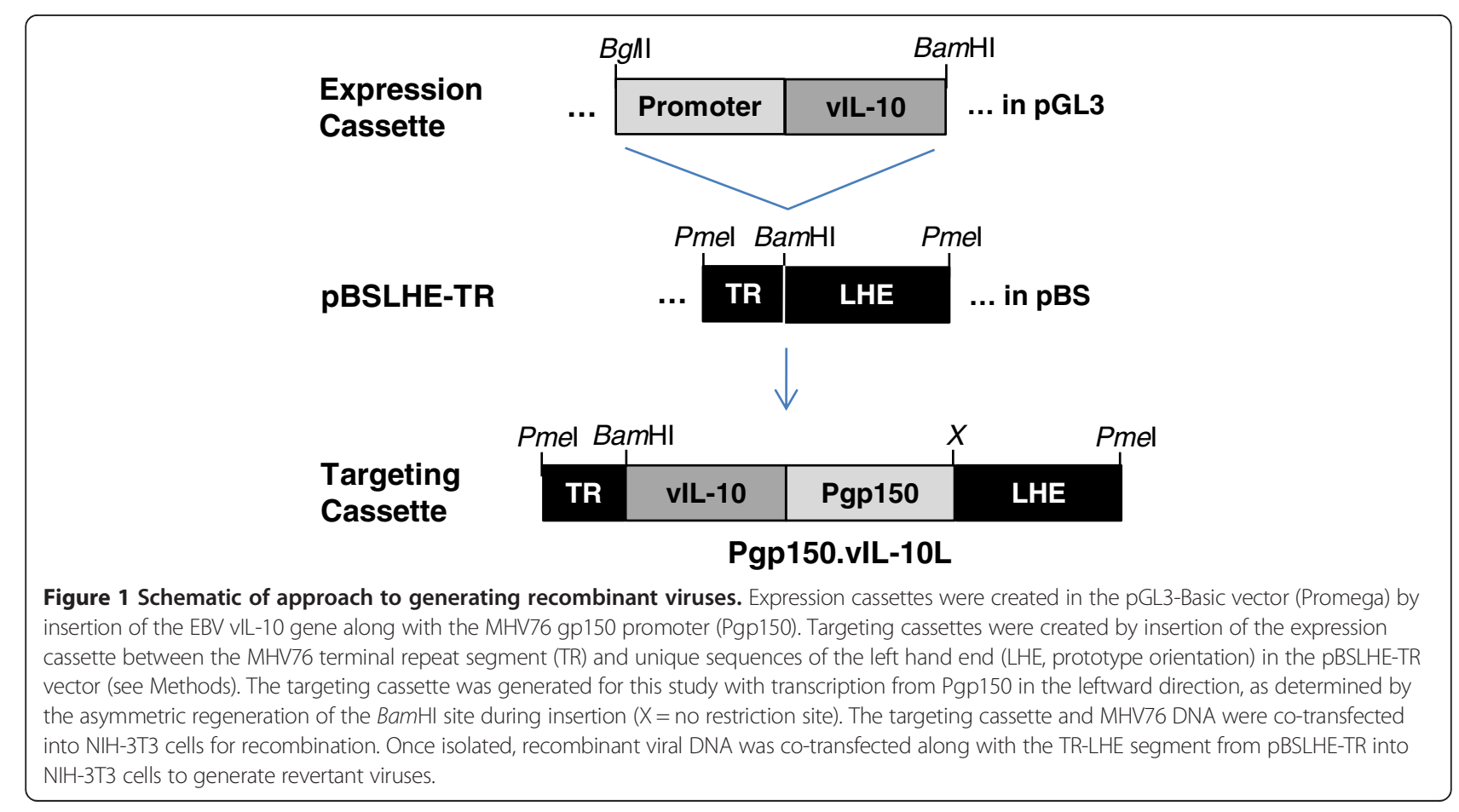


confirmed vIL-10 expression from recombinant viruses in infected NIH-3T3 cells. Revertant control viruses were generated using the preceding procedures by co-transfection of cell cultures with recombinant virus DNA and the TR-LHE fragment lacking an expression cassette insert. All recombinant DNA work was conducted under protocols approved by the Institutional Biosafety Committee following US federal guidelines.

\section{In vitro growth curves}

NIH-3T3 cell cultures (70-80\% confluent) were infected at a multiplicity of infection (MOI) of 5 . Virus was allowed to adsorb for one hour at $37^{\circ} \mathrm{C}$, and cells were washed three times with fresh medium to remove unbound virus. Samples were taken at time zero and appropriate time points thereafter by scraping the cells and collecting by aspiration. Cells were freeze-thawed three times to release cell-associated virus, and viral titers were determined by plaque assay.

\section{Inoculation and sampling of mice}

Four- to six-week-old male BALB/c mice (Jackson Laboratories) under light anesthesia (isoflurane, 1.5-2.5\%, by inhalation) were inoculated i.n. with $2 \times 10^{5}$ pfu virus [45]. At various times p.i., mice were euthanized by $\mathrm{CO}_{2}$ asphyxiation followed by cervical dislocation. Lungs were removed and snap frozen. Spleens were removed and held briefly in tissue culture medium. After spleens were weighed, they were homogenized by passage through a mesh screen, and red blood cells were lysed in Red Blood Cell Lysing Buffer (Sigma-Aldrich). Leukocytes were recovered from the pellet following centrifugation by resuspension in tissue culture medium, and aliquots of cells were counted to calculate number of leukocytes per spleen. All animal work was conducted under protocols approved by the Institutional Animal Care and Use Committee following US federal guidelines.

\section{Quantification of lytic virus}

Spleens and lungs were harvested from euthanized mice various days p.i. and homogenized (Mini-BeadBeater-8, as described [36]). Supernatants were freeze-thawed and clarified by centrifugation. Virus titers were determined by plaque assay of serial dilutions on NIH-3T3 cells.

\section{Quantification of latent virus}

Viral DNA was detected using a limiting-dilution, nested PCR assay for the MHV-68 ORF50 gene with single-copy sensitivity essentially as described $[32,50]$.

\section{Reactivation assay}

The limiting-dilution assay as described by Weck [36] was used to assess reactivation from latently infected spleen cells. Briefly, mouse embryonic fibroblast (MEF) cells (ATCC), were plated in 96-well culture plates and inoculated with limiting-dilutions of splenic leukocytes or splenic-cell lysates, and results were analyzed after 14-21 days with subtraction of any detectable lytic virus present in the lysate. Statistical analysis of all experiments was conducted using GraphPad Prism software.

\section{Results \\ Construction of recombinant MHV-76 and expression of vIL-10}

For expression of the EBV vIL-10 gene in MHV-76, we utilized the MHV-68 M7 late-gene promoter which allows transcription of the gp150 protein. A 660-bp fragment from upstream of the gp150 start codon was amplified by PCR and inserted directly upstream of the luciferase gene in Promega's pGL3-basic vector. The promoter was successful in driving expression of luciferase when the plasmid was transfected into NIH-3T3 cells with or without MHV-76 viral infection (data not shown). The luciferase coding sequences were then replaced with the coding sequences for EBV vIL-10. The new constructs were successful in expressing vIL-10 in NIH-3T3 cells with similar expression levels in uninfected cells and in cells infected with MHV-76 (Figure 2).

The gp150-promoter/vIL-10 cassette was then inserted between the terminal repeat and the unique sequences of the left hand end of the cloned MHV-76 DNA to create the targeting cassette (Figure 1). The targeting cassette was liberated from its plasmid by restriction enzyme digestion and co-transfected with MHV-76 DNA into NIH-3T3 cells to allow for recombination within the TR and LHE sequences, effectively inserting the vIL-10 gene into the MHV-76 genome. Putative recombinant viruses (designated 76.vIL10) were screened by PCR upon multiple rounds of limiting-dilution infections in vitro until a purified culture of vIL-10 PCR-positive virus was obtained. Expression of vIL-10 by recombinant viruses was confirmed by ELISA, which demonstrated a mean concentration of vIL-10 three days p.i. in cell culture supernatant of $11 \mathrm{ng} / \mathrm{ml}$ (standard deviation $=5.5 \mathrm{ng} / \mathrm{ml}$; three trials with duplicate samples per trial). Finally, recombinant virus was co-transfected with a fragment containing the TR-LHE contiguous sequence in order to create a revertant virus strain (designated 76.rev). Insertion and integrity of the promoter and gene sequences were confirmed by DNA sequence analysis and MHV-76, 76. vIL10, 76.rev, and MHV-68 virus strains all were shown to have very similar in vitro growth rates (Figure 3 ).

\section{vlL-10 enhances acute viral titers in lungs}

Previous studies have shown that MHV-76 titer in infected-mouse lungs peaks at day 4 p.i., while MHV-68 titer peaks significantly higher and at day 6 p.i. [45]. In these experiments (Figure 4), viral titers in lungs at day 


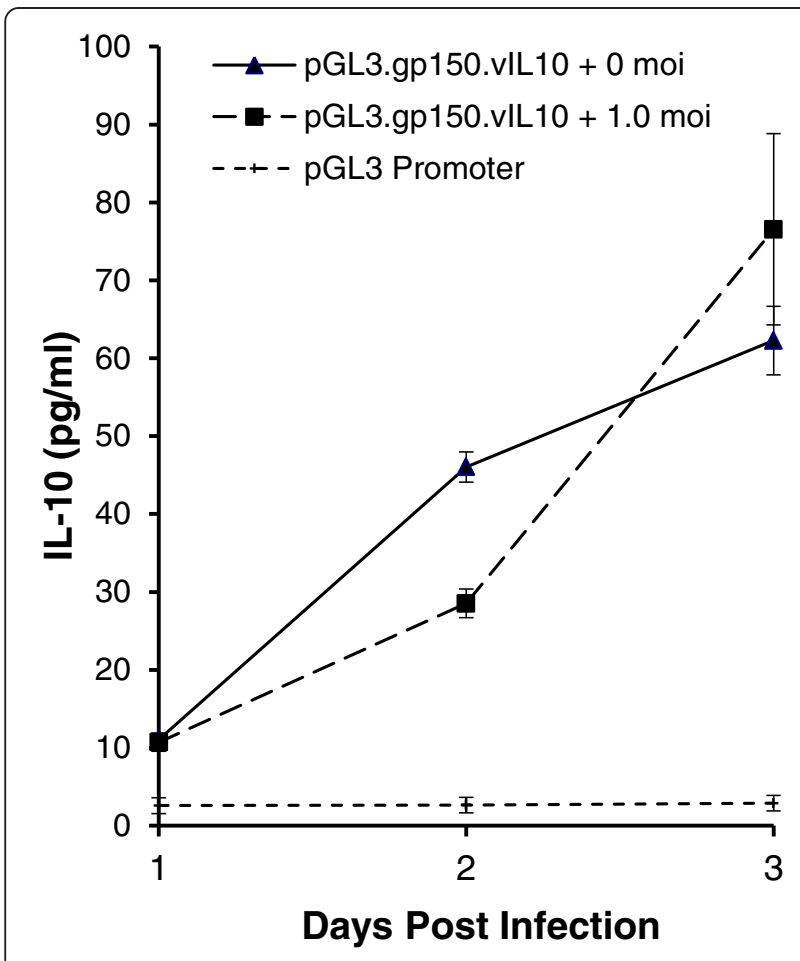

Figure 2 vIL-10 is expressed in transfected cells. $\mathrm{NIH}-3 \mathrm{~T} 3$ cells were transfected with plasmid containing the Pgp150.vlL10 expression cassette or control plasmid (pGL3-Promoter) and infected or not with MHV-76 at a MOI of 1. After 24, 36, and 48 hours, supernatant was tested for the presence of VIL-10 by ELISA. Data points represent the averages of two readings of each sample in duplicate experiments. Error bars indicate $+/-1$ standard deviation.

5 p.i. were significantly higher for the recombinant 76.vIL10 than either MHV-76 $(P=0.0025)$ or the revertant control strain, 76.rev $(P<0.0001)$. These results demonstrate that vIL-10 allows enhanced acute viral titers in lungs. Furthermore, no significant difference was seen in titers at this time point for MHV-68 versus 76.vIL10. While MHV-68 titers were significantly higher than those of 76.rev $(P=0.0076)$, the marginally higher mean titer of MHV-68 versus MHV-76 was not significant.

vIL-10 promotes an increase in spleen cell number

The development of splenomegaly, a characteristic of MHV acute phase infection that normally peaks from day 10-14 p.i., was assessed by determining the total number of leucocytes in infected-mouse spleens. Splenocyte counts were determined at days 10, 14, and 21 p.i. (Figure 5). As expected [45], MHV-68 compared to MHV-76 resulted in a significant increase in number of splenocytes throughout the measured course of infection, with peak expansion of the population at day 14 (day $10, P=0.0106$; day 14 , $P<0.0001$; day $21, P=0.0005)$. Splenocyte counts peaked at day 10 p.i. in mice infected with either the

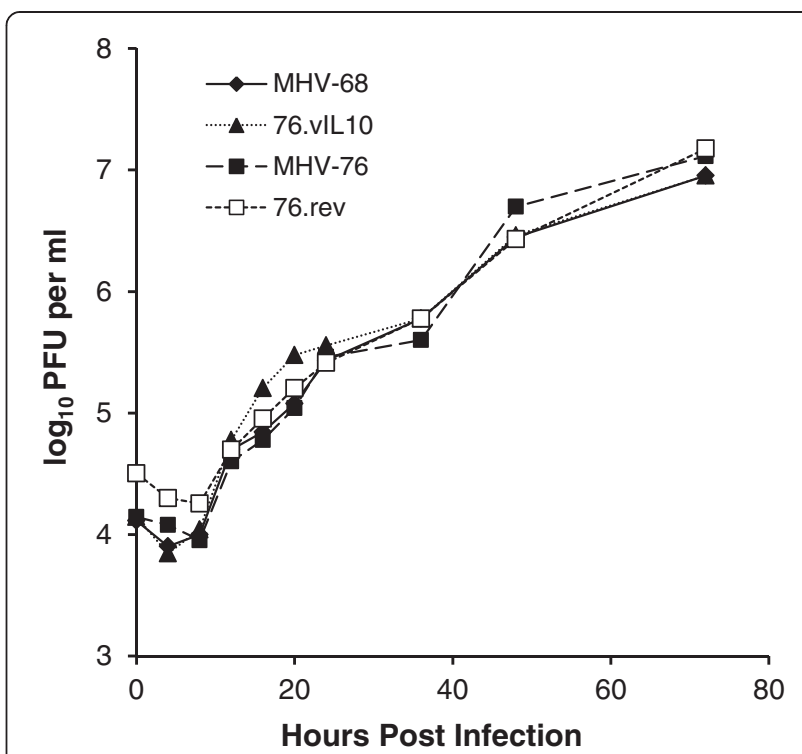

Figure 3 Viruses have equivalent in vitro growth properties. $\mathrm{NIH}-3 \mathrm{~T} 3$ cells were infected at a MOI of 5. Cells were harvested at various times post-infection, and viral titers were determined in duplicate. Data points represent average titers at each sampling time.

vIL-10-containing strain 76.vIL10, or its parent strain, MHV-76. However, at day 14 p.i., 76.IL10-infected mice had a significantly greater number of splenocytes than MHV-76-infected mice $(P<0.0001)$. Thus, while expression of vIL-10 did not appear to affect the

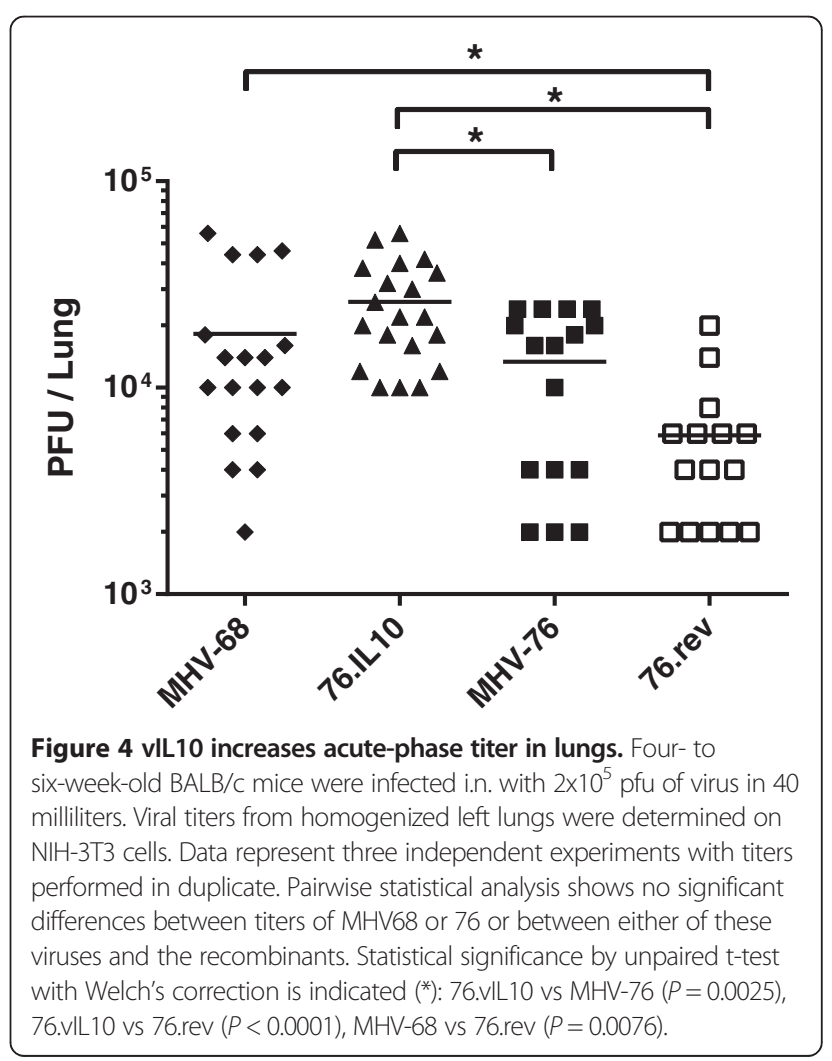


timing of the splenocyte expansion, it did increase its magnitude.

vIL-10 does not alter the quantity of latent virus in spleen cells or its ability to reactivate

The presence of viral genomes in splenocytes early in latency was assayed by limiting-dilution PCR. Previous studies have shown a defect in latency for MHV-76 as compared to MHV-68 following i.n. inoculation [44,45]. While Figure 6 does not exhibit a significant difference in PCR-positive cells for the sample size and dilutions tested, MHV-68 trends toward a higher number of positive cells, and MHV-76 and 76.vIL10 track together. Importantly, the expected differences in reactivation between MHV-68 and MHV-76 [44,45] are observed in Figure 7. Data indicate no significant difference in reactivation of MHV76 with or without vIL-10.

\section{Discussion}

These results provide the first evidence of vIL-10's role in gammaherpesvirus infection in an in vivo model of viral pathogenicity. vIL-10 expression in MHV-76infected mice increases acute-phase pathogenicity, but does not increase the percentage of latently infected splenocytes or the level of reactivation of latent virus. In accordance with these findings, in EBV, in which vIL-10

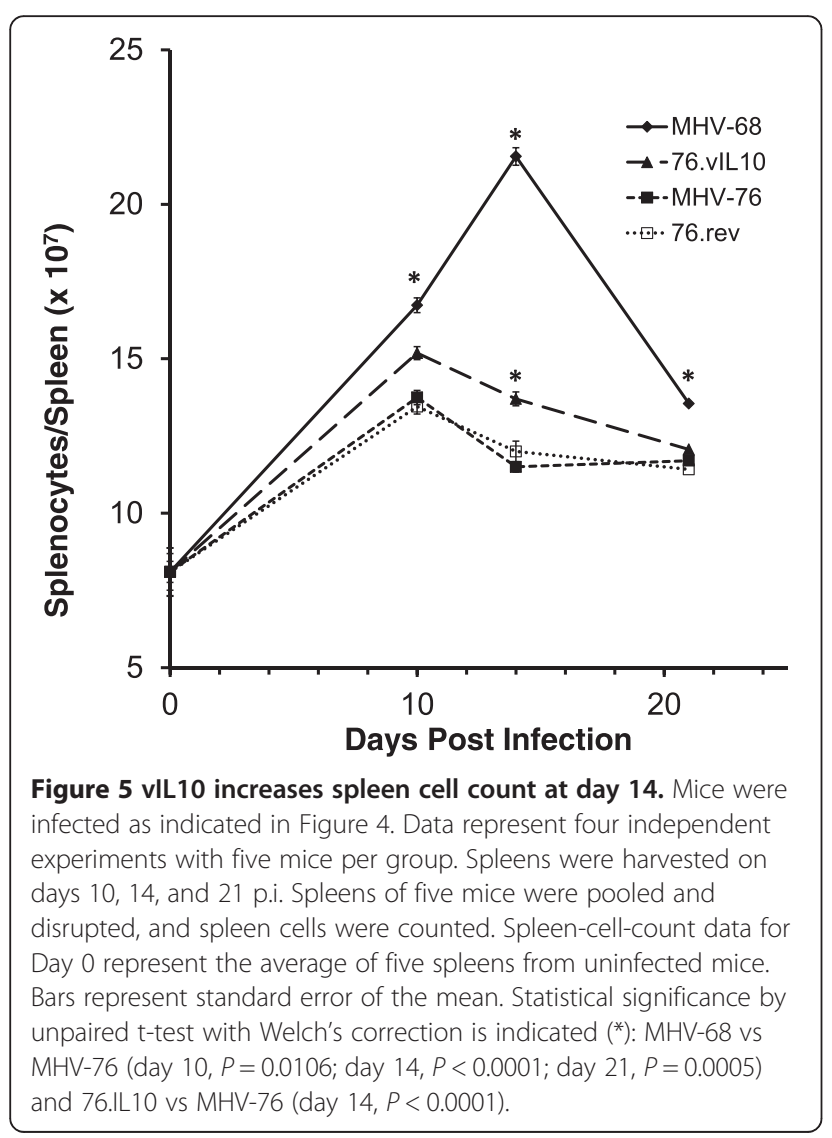

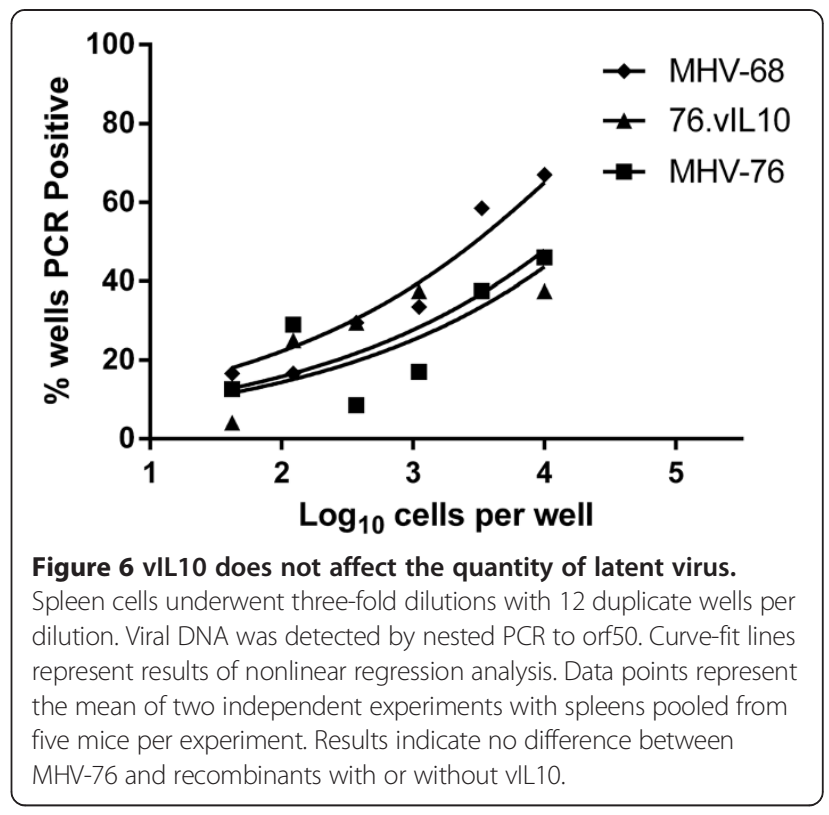

is expressed in its native environment, several studies have associated the gene's expression with the acute phase of infection $[13,21,55]$.

Nevertheless, IL-10 and its ability to drive B cell proliferation and differentiation into plasma cells are considered significant factors in the process of gammaherpesvirus reactivation from latency. The MHV-68 M2 gene product stimulates cIL-10 expression and subsequent B cell proliferation and differentiation [51]. The M2 protein exerts this effect by activating the NFAT signal transduction pathway which induces expression of interferon regulatory factor-4 (IRF-4), in turn inducing cIL-10 expression [52]. cIL-10 expression is also induced in EBV-infected cells by latencyassociated LMP-1 and small non-coding RNAs (EBERs) $[15,16]$, and in Kaposi's sarcoma-associated herpesvirus (KSHV) by viral-encoded miRNA [56]. Whether vIL-10 plays a role in EBV infection in the human similar to that of cIL-10 induction by MHV-68's M2 protein in the mouse remains to be shown. However, with EBV's other means of inducing cIL-10 during latency, it is possible that EBV expression of vIL-10 serves a different function. Results presented in this paper suggest that vIL-10's role may be in enhancing infection during the acute (lytic) phase.

Early expression of vIL-10 homologues by herpesviruses appears to increase the local pool of host cells permissive for infection, thus increasing the chance for trafficking of infected cells to other sites. For example, human cytomegalovirus (HCMV) and RhCMV encode IL-10 homologs that induce the differentiation of macrophages [25], a cell type shown to be permissive for CMV infection $[57,58]$. Our results have shown that EBV vIL-10 expression by MHV-76 increases splenomegaly, where MHVinduced splenomegaly results, in part, from an increase in 


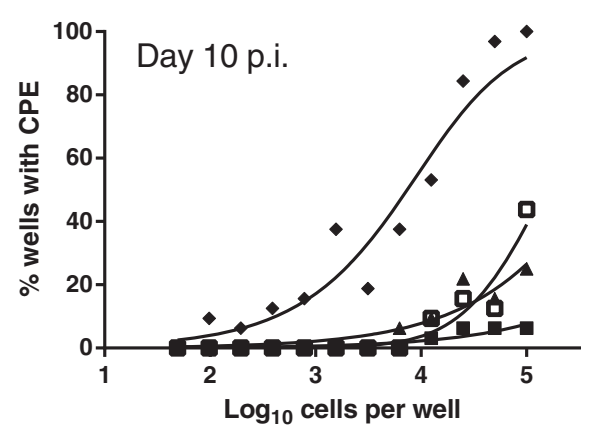

$$
\begin{aligned}
& \rightarrow \text { MHV-68 } \\
& +76 . v I L 10 \\
& \rightarrow \text { MHV-76 } \\
& \rightarrow 76 . r e v
\end{aligned}
$$
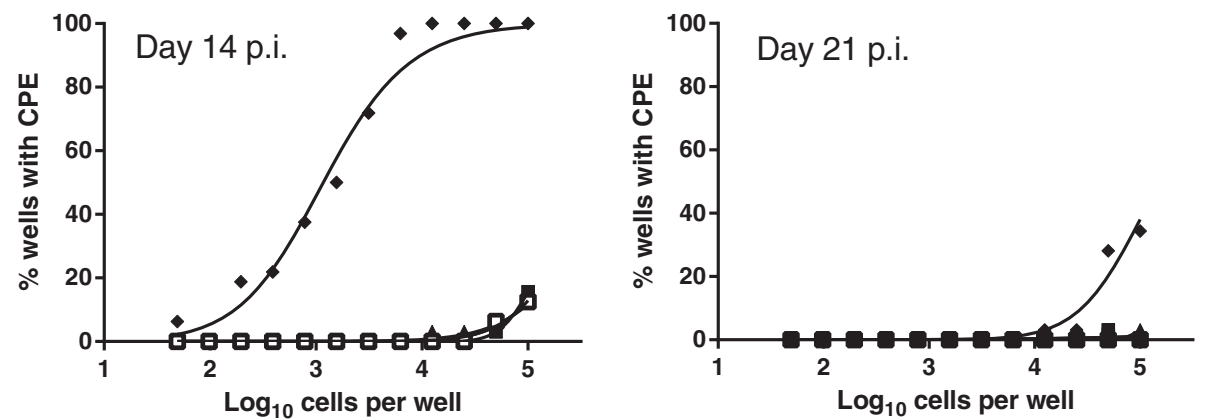

Figure 7 vIL10 does not affect the quantity of reactivating virus. Spleen cells were plated atop MEF cells in dilutions across 96-well plates as indicated on the $x$-axes with 16 duplicate wells per dilution. Wells were scored for CPE on days 10, 14 and 21. Curve-fit lines represent results of nonlinear regression analysis. Data points represent the mean of two independent experiments with spleens pooled from five mice per experiment. Results indicate no difference between MHV-76 and recombinants with or without vIL10.

B cells [29], and infected B cells are likely vehicles for trafficking MHV-68 from the lung epithelium to the spleen [37].

In addition to increasing the pool of host cells to expand and disseminate primary infection, early expression of viral IL-10 homologues reduces virus-specific effector responses, helping to ensure the survival of infected cells into the latent phase. Such inhibition can occur upstream of effector cell activation by inhibiting innate responses critical to the transition to adaptive immunity. RhCMV IL-10 reduces dendritic cell populations in draining lymph nodes, resulting in a lower frequency of virus-specific $\mathrm{T}$ cells [25]. EBV vIL-10 modulates cytokine responses [12], reduces MHC I expression [59], avoids increasing MHC II expression [20], and inhibits monocytes [60]. vIL-10 can also inhibit effector cell responses directly. For example, vIL-10 limits NK cell killing of infected B cells and inhibits CD4+ T cell activity [12]. Studies are planned that will assess effector responses in mice infected with 76.vIL-10.

The timing and level of expression of vIL-10 are likely to relate significantly to vIL-10's influence on pathogenicity. Expression of vIL-10 by the recombinant virus used in this study was quantified by an ELISA that distinguished vIL-10 from any cIL-10 that might have been produced by host cells. However, it is difficult to know how this level of expression compares to expression of vIL-10 in EBV-infected cells. Published studies have reported vIL-10 concentrations in functional units [14] or fluorescence units [61] rather than in units of mass. Furthermore, the difference in culture conditions for recombinant MHV and EBV would make such comparisons difficult to interpret. Finally, it would be of interest to determine if recombinant viruses package vIL-10 mRNA in the virion and express the product immediately upon infection as has been shown for EBV [12] as well as to ascertain the kinetics of expression of vIL-10 by recombinant MHV in the host animal.

Details are emerging to clarify our understanding of viral modulation of immune responses via cIL-10 and vIL-10. Such understanding may expand our ability to intervene in diseases such as EBV-associated lymphoproliferative disease [62]. Several studies have exploited the immunomodulatory properties of EBV vIL-10 for increasing the survival of allografts [63-70]. The establishment of this model murine gammaherpesvirus expressing vIL-10 may contribute further to such work.

\section{Conclusions}

In this mouse model of gammaherpesvirus infection, EBV vIL-10 appears to influence the acute-phase pathogenicity by increasing the viral titers in lungs and increasing the number of spleen cells, resulting in enhanced splenomegaly. However, following the establishment of latency, vIL-10 expressing strains showed no difference in the percentage 
of latently infected spleen cells or in the ability of virus to reactivate. Given that EBV and MHV contain other genes that induce cIL-10 expression in latency (e.g. LMP-1 and M2, respectively), vIL-10 may have evolved to serve the specific role in acute infection of enlarging the permissive host cell population, perhaps to facilitate dissemination and initial survival of viral-infected cells.

\section{Competing interests}

The authors declare that they have no competing of interest.

\section{Authors' contributions}

GL conceived of the study; GL, JPS and JTS designed the study. KG helped generate recombinant herpesviruses and conducted growth curve experiments and animal studies. GL coordinated all and conducted many of the experiments and wrote the manuscript. All authors have approved the final manuscript.

\section{Acknowledgments}

For technical assistance, we thank Drew Burk, Kristen Campbell, Joiceann Compton, Chris Davis, Meghan Davis, Carol Dickerson, Jeff Freyder, Lauren Jackson, Kristina Lynch, Audrey Marsidi, Megan McKenna, Sandra Obreza, and Desiree Steimer. For advice, reagents and/or sponsorship, we thank Laurie Krug and Peter Doherty. This work was funded by the National Institutes of Health [5 R01 CA90208 (JTS); 1 R15 Al068680 (GJL)] and Rhodes College Faculty Development Endowment.

\section{Author details}

'Department of Biology, Rhodes College, Memphis, TN 38112, USA. ${ }^{2}$ Department of Infection Biology, Institute of Infection and Global Health, University of Liverpool, Liverpool L3 5RF, UK. ${ }^{3}$ Department of Biochemistry, St. Jude Children's Research Hospital, Memphis, TN 38105, USA. ${ }^{4}$ Current Address: Department of Microbiology and Immunology, The Pennsylvania State University College of Medicine, Hershey, PA 17033, USA.

Received: 1 April 2014 Accepted: 21 September 2014 Published: 24 September 2014

\section{References}

1. Alcami A, Koszinowski UH: Viral mechanisms of immune evasion. Trends Microbiol 2000, 8:410-418.

2. Tortorella D, Gewurz BE, Furman MH, Schust DJ, Ploegh HL: Viral subversion of the immune system. Annu Rev Immunol 2000, 18:861-926.

3. Alcami A: Viral mimicry of cytokines, chemokines and their receptors. Nat Rev Immunol 2003, 3:36-50.

4. Moore KW, Vieira P, Fiorentino DF, Trounstine ML, Khan TA, Mosmann TR: Homology of cytokine synthesis inhibitory factor (IL-10) to the Epstein-Barr virus gene BCRFI. Science 1990, 248:1230-1234.

5. Telford EA, Watson MS, Aird HC, Perry J, Davison AJ: The DNA sequence of equine herpesvirus 2. J Mol Biol 1995, 249:520-528.

6. Jayawardane G, Russell GC, Thomson J, Deane D, Cox H, Gatherer D, Ackermann M, Haig DM, Stewart JP: A captured viral interleukin 10 gene with cellular exon structure. J Gen Virol 2008, 89:2447-2455.

7. Raftery MJ, Wieland D, Gronewald S, Kraus AA, Giese T, Schonrich G: Shaping phenotype, function, and survival of dendritic cells by cytomegalovirus-encoded IL-10. J Immunol 2004, 173:3383-3391.

8. Lockridge KM, Zhou SS, Kravitz RH, Johnson JL, Sawai ET, Blewett EL, Barry PA: Primate cytomegaloviruses encode and express an IL-10-like protein. Virology 2000, 268:272-280.

9. Kotenko SV, Saccani S, Izotova LS, Mirochnitchenko OV, Pestka S: Human cytomegalovirus harbors its own unique IL-10 homolog (cmvlL-10). Proc Natl Acad Sci U S A 2000, 97:1695-1700.

10. Miyazaki I, Cheung RK, Dosch HM: Viral interleukin 10 is critical for the induction of $B$ cell growth transformation by Epstein-Barr virus. J Exp Med 1993, 178:439-447.

11. Swaminathan S, Hesselton R, Sullivan J, Kieff E: Epstein-Barr virus recombinants with specifically mutated BCRF1 genes. J Virol 1993, $67: 7406-7413$
12. Jochum S, Ruiss R, Moosmann A, Hammerschmidt W, Zeidler R: RNAs in Epstein-Barr virions control early steps of infection. Proc Natl Acad Sci U S A 2012, 109:E1396-1404.

13. Burdin N, Peronne C, Banchereau J, Rousset F: Epstein-Barr virus transformation induces B lymphocytes to produce human interleukin 10. J Exp Med 1993, 177:295-304.

14. Taga H, Taga K, Wang F, Chretien J, Tosato G: Human and viral interleukin-10 in acute Epstein-Barr virus-induced infectious mononucleosis. J Infect Dis 1995, 171:1347-1350

15. Nakagomi H, Dolcetti R, Bejarano MT, Pisa P, Kiessling R, Masucci MG: The Epstein-Barr virus latent membrane protein-1 (LMP1) induces interleukin-10 production in Burkitt lymphoma lines. Int J Cancer 1994, 57:240-244.

16. Kitagawa N, Goto M, Kurozumi K, Maruo S, Fukayama M, Naoe T, Yasukawa M, Hino K, Suzuki T, Todo S, Takada K: Epstein-Barr virus-encoded poly(A)(-) RNA supports Burkitt's lymphoma growth through interleukin-10 induction. Embo J 2000, 19:6742-6750.

17. Moore KW, de Waal MR, Coffman RL, O'Garra A: Interleukin-10 and the interleukin-10 receptor. Annu Rev Immunol 2001, 19:683-765.

18. Hsu DH, de Waal MR, Fiorentino DF, Dang MN, Vieira P, de Vries J, Spits H, Mosmann TR, Moore KW: Expression of interleukin-10 activity by EpsteinBarr virus protein BCRF1. Science 1990, 250:830-832.

19. Zdanov A, Schalk-Hihi C, Wlodawer A: Crystal structure of human interleukin-10 at 1.6 A resolution and a model of a complex with its soluble receptor. Protein Sci 1996, 5:1955-1962.

20. Go NF, Castle BE, Barrett R, Kastelein R, Dang W, Mosmann TR, Moore KW, Howard M: Interleukin 10, a novel B cell stimulatory factor: unresponsiveness of $\mathrm{X}$ chromosome-linked immunodeficiency $\mathrm{B}$ cells. $J$ Exp Med 1990, 172:1625-1631.

21. Vieira P, de Waal-Malefyt R, Dang MN, Johnson KE, Kastelein R, Fiorentino DF, de Vries JE, Roncarolo MG, Mosmann TR, Moore KW: Isolation and expression of human cytokine synthesis inhibitory factor CDNA clones: homology to Epstein-Barr virus open reading frame BCRFI. Proc Natl Acad Sci U S A 1991, 88:1172-1176.

22. MacNeil IA, Suda T, Moore KW, Mosmann TR, Zlotnik A: IL-10, a novel growth cofactor for mature and immature T cells. J Immunol 1990, 145:4167-4173.

23. Liu Y, de Waal MR, Briere F, Parham C, Bridon JM, Banchereau J, Moore KW $\mathrm{Xu}$ J: The EBV IL-10 homologue is a selective agonist with impaired binding to the IL-10 receptor. J Immunol 1997, 158:604-613.

24. Ding Y, Qin L, Kotenko SV, Pestka S, Bromberg JS: A single amino acid determines the immunostimulatory activity of interleukin 10. J Exp Med 2000, 191:213-224.

25. Chang WL, Barry PA: Attenuation of innate immunity by cytomegalovirus IL-10 establishes a long-term deficit of adaptive antiviral immunity. Proc Natl Acad Sci U S A 2010, 107:22647-22652.

26. Jones BC, Logsdon NJ, Josephson K, Cook J, Barry PA, Walter MR: Crystal structure of human cytomegalovirus IL-10 bound to soluble human IL-10R1. Proc Natl Acad Sci U S A 2002, 99:9404-9409.

27. Olivadoti $M$, Toth LA, Weinberg J, Opp MR: Murine gammaherpesvirus 68 a model for the study of Epstein-Barr virus infections and related diseases. Comp Med 2007, 57:44-50.

28. Sunil-Chandra NP, Efstathiou S, Arno J, Nash AA: Virological and pathological features of mice infected with murine gamma-herpesvirus 68. J Gen Virol 1992, 73(Pt 9):2347-2356.

29. Usherwood EJ, Ross AJ, Allen DJ, Nash AA: Murine gammaherpesvirusinduced splenomegaly: a critical role for CD4 T cells. J Gen Virol 1996, 77(Pt 4):627-630.

30. Stevenson PG, Doherty PC: Non-antigen-specific B-cell activation following murine gammaherpesvirus infection is CD4 independent in vitro but CD4 dependent in vivo. J Virol 1999, 73:1075-1079.

31. Tripp RA, Hamilton-Easton AM, Cardin RD, Nguyen P, Behm FG, Woodland $D L$, Doherty PC, Blackman MA: Pathogenesis of an infectious mononucleosis-like disease induced by a murine gamma-herpesvirus: role for a viral superantigen? J Exp Med 1997, 185:1641-1650.

32. Weck KE, Kim SS, Virgin HI, Speck SH: Macrophages are the major reservoir of latent murine gammaherpesvirus 68 in peritoneal cells. J Virol 1999 73:3273-3283.

33. Flano E, Husain SM, Sample JT, Woodland DL, Blackman MA: Latent murine gamma-herpesvirus infection is established in activated $B$ cells, dendritic cells, and macrophages. J Immuno/ 2000, 165:1074-1081. 
34. Sunil-Chandra NP, Efstathiou S, Nash AA: Murine gammaherpesvirus 68 establishes a latent infection in mouse B lymphocytes in vivo. J Gen Virol 1992, 73(Pt 12):3275-3279.

35. Sunil-Chandra NP, Efstathiou S, Nash AA: Interactions of murine gammaherpesvirus 68 with B and T cell lines. Virology 1993, 193:825-833.

36. Weck KE, Barkon ML, Yoo LI, Speck SH, Virgin HI: Mature B cells are required for acute splenic infection, but not for establishment of latency, by murine gammaherpesvirus 68. J Virol 1996, 70:6775-6780.

37. Stewart JP, Usherwood EJ, Ross A, Dyson H, Nash T: Lung epithelial cells are a major site of murine gammaherpesvirus persistence. J Exp Med 1998, 187:1941-1951.

38. Bowden RJ, Simas JP, Davis AJ, Efstathiou S: Murine gammaherpesvirus 68 encodes tRNA-like sequences which are expressed during latency. J Gen Virol 1997, 78(Pt 7):1675-1687.

39. Simas JP, Bowden RJ, Paige V, Efstathiou S: Four tRNA-like sequences and a serpin homologue encoded by murine gammaherpesvirus 68 are dispensable for lytic replication in vitro and latency in vivo. $J$ Gen Virol 1998, 79(Pt 1):149-153.

40. Simas JP, Efstathiou S: Murine gammaherpesvirus 68: a model for the study of gammaherpesvirus pathogenesis. Trends Microbiol 1998, 6:276-282.

41. Ehtisham S, Sunil-Chandra NP, Nash AA: Pathogenesis of murine gammaherpesvirus infection in mice deficient in CD4 and CD8 T cells. J Virol 1993, 67:5247-5252.

42. Doherty PC, Topham DJ, Tripp RA, Cardin RD, Brooks JW, Stevenson PG: Effector CD4+ and CD8+ T-cell mechanisms in the control of respiratory virus infections. Immunol Rev 1997, 159:105-117.

43. Stevenson PG, Belz GT, Castrucci MR, Altman JD, Doherty PC: A gammaherpesvirus sneaks through a $C D 8(+) T$ cell response primed to a lytic-phase epitope. Proc Natl Acad Sci U S A 1999, 96:9281-9286.

44. Clambey ET, Virgin HW, Speck SH: Characterization of a spontaneous 9.5-kilobase-deletion mutant of murine gammaherpesvirus 68 reveals tissue-specific genetic requirements for latency. J Virol 2002, 76:6532-6544

45. Macrae Al, Dutia BM, Milligan S, Brownstein DG, Allen DJ, Mistrikova J, Davison AJ, Nash AA, Stewart JP: Analysis of a novel strain of murine gammaherpesvirus reveals a genomic locus important for acute pathogenesis. J Virol 2001, 75:5315-5327.

46. Husain SM, Usherwood EJ, Dyson H, Coleclough C, Coppola MA, Woodland DL, Blackman MA, Stewart JP, Sample JT: Murine gammaherpesvirus M2 gene is latency-associated and its protein a target for CD8(+) T lymphocytes. Proc Natl Acad Sci U S A 1999, 96:7508-7513.

47. Madureira PA, Matos P, Soeiro I, Dixon LK, Simas JP, Lam EW: Murine gamma-herpesvirus 68 latency protein $M 2$ binds to Vav signaling proteins and inhibits B-cell receptor-induced cell cycle arrest and apoptosis in WEHI-231 B cells. J Biol Chem 2005, 280:37310-37318.

48. Jacoby MA, Virgin HW, Speck SH: Disruption of the M2 gene of murine gammaherpesvirus 68 alters splenic latency following intranasal, but not intraperitoneal, inoculation. J Virol 2002, 76:1790-1801.

49. Macrae Al, Usherwood EJ, Husain SM, Flano E, Kim IJ, Woodland DL, Nash AA, Blackman MA, Sample JT, Stewart JP: Murid herpesvirus 4 strain 68 M2 protein is a B-cell-associated antigen important for latency but not lymphocytosis. J Virol 2003, 77:9700-9709.

50. Herskowitz J, Jacoby MA, Speck SH: The murine gammaherpesvirus $68 \mathrm{M} 2$ gene is required for efficient reactivation from latently infected B cells. $J$ Virol 2005, 79:2261-2273.

51. Siegel AM, Herskowitz JH, Speck SH: The MHV68 M2 protein drives IL-10 dependent B cell proliferation and differentiation. PLoS Pathog 2008, 4:e1000039.

52. Rangaswamy US, Speck SH: Murine gammaherpesvirus M2 protein induction of IRF4 via the NFAT pathway leads to IL-10 expression in B cells. PLOS Pathog 2014, 10:e1003858.

53. Douglas J, Dutia B, Rhind S, Stewart JP, Talbot SJ: Expression in a recombinant murid herpesvirus 4 reveals the in vivo transforming potential of the K1 open reading frame of Kaposi's sarcoma-associated herpesvirus. J Virol 2004, 78:8878-8884.

54. Efstathiou S, Ho YM, Minson AC: Cloning and molecular characterization of the murine herpesvirus 68 genome. J Gen Virol 1990, 71(Pt 6):1355-1364.

55. Stewart JP, Rooney CM: The interleukin-10 homolog encoded by EpsteinBarr virus enhances the reactivation of virus-specific cytotoxic $T$ cell and HLA-unrestricted killer cell responses. Virology 1992, 191:773-782.
56. Qin Z, Kearney P, Plaisance K, Parsons CH: Pivotal advance: Kaposi's sarcoma-associated herpesvirus (KSHV)-encoded microRNA specifically induce IL- 6 and IL-10 secretion by macrophages and monocytes. J Leukoc Biol 2010, 87:25-34.

57. Sinzger C, Plachter B, Grefte A, The TH, Jahn G: Tissue macrophages are infected by human cytomegalovirus in vivo. J Infect Dis 1996, 173:240-245.

58. Ibanez CE, Schrier R, Ghazal P, Wiley C, Nelson JA: Human cytomegalovirus productively infects primary differentiated macrophages. J Virol 1991, 65:6581-6588.

59. Zeidler R, Eissner G, Meissner P, Uebel S, Tampe R, Lazis S, Hammerschmidt W: Downregulation of TAP1 in B lymphocytes by cellular and Epstein-Barr virus-encoded interleukin-10. Blood 1997, 90:2390-2397.

60. Salek-Ardakani S, Arrand JR, Mackett M: Epstein-Barr virus encoded interleukin-10 inhibits HLA-class I, ICAM-1, and B7 expression on human monocytes: implications for immune evasion by EBV. Virology 2002, 304:342-351.

61. Sairenji T, Ohnishi E, Inouye $S$, Kurata T: Induction of interleukin-10 on activation of Epstein-Barr virus in EBV-infected B-cell lines. Viral Immunol 1998, 11:221-231.

62. Suzuki T, Tahara H, Narula S, Moore KW, Robbins PD, Lotze MT: Viral interleukin 10 (IL-10), the human herpes virus 4 cellular IL-10 homologue, induces local anergy to allogeneic and syngeneic tumors. J Exp Med 1995, 182:477-486.

63. Salgar SK, Yang D, Ruiz P, Miller J, Tzakis AG: Viral interleukin-10 gene therapy to induce tolerance to solid organ transplants in mice. Transplant Proc 2004, 36:397-398.

64. Salgar SK, Yang D, Ruiz P, Miller J, Tzakis AG: Viral interleukin-10-engineered autologous hematopoietic stem cell therapy: a novel gene therapy approach to prevent graft rejection. Hum Gene Ther 2004, 15:131-144.

65. Benhamou PY, Mullen Y, Shaked A, Bahmiller D, Csete ME: Decreased alloreactivity to human islets secreting recombinant viral interleukin 10 . Transplantation 1996, 62:1306-1312.

66. Wang CK, Zuo XJ, Carpenter D, Jordan S, Nicolaidou E, Toyoda M, Czer LS, Wang $H$, Trento A: Prolongation of cardiac allograft survival with intracoronary viral interleukin-10 gene transfer. Transplant Proc 1999, 31:951-952.

67. Brauner R, Wu L, Laks H, Nonoyama M, Scholl F, Shvarts O, Berk A, Drinkwater DC Jr, Wang JL: Intracoronary gene transfer of immunosuppressive cytokines to cardiac allografts: method and efficacy of adenovirus-mediated transduction. J Thorac Cardiovasc Surg 1997, 113:1059-1066. discussion 1066-1057.

68. DeBruyne LA, Li K, Chan SY, Qin L, Bishop DK, Bromberg JS: Lipid-mediated gene transfer of viral IL-10 prolongs vascularized cardiac allograft survival by inhibiting donor-specific cellular and humoral immune responses. Gene Ther 1998, 5:1079-1087.

69. Qin L, Chavin KD, Ding Y, Tahara H, Favaro JP, Woodward JE, Suzuki T, Robbins PD, Lotze MT, Bromberg JS: Retrovirus-mediated transfer of viral IL-10 gene prolongs murine cardiac allograft survival. J Immunol 1996, 156:2316-2323.

70. Qin L, Ding Y, Pahud DR, Robson ND, Shaked A, Bromberg JS: Adenovirusmediated gene transfer of viral interleukin-10 inhibits the immune response to both alloantigen and adenoviral antigen. Hum Gene Ther 1997, 8:1365-1374.

doi:10.1186/2042-4280-5-1

Cite this article as: Lindquester et al:: Epstein-Barr virus IL-10 gene expression by a recombinant murine gammaherpesvirus in vivo enhances acute pathogenicity but does not affect latency or reactivation. Herpesviridae 2014 5:1. 